\title{
ПРИМЕНЕНИЕ ДИСТАНЦИОННЫХ ОБРАЗОВАТЕЛЬНЫХ ТЕХНОЛОГИЙ В ОБУЧЕНИИ ЛИЦ С ОГРАНИЧЕННЫМИ ВОЗМОЖНОСТЯМИ ЗДОРОВЬЯ
}

\author{
Джуманова Ольга Анатольевна \\ преподаватель \\ Государственное бюджетное профессиональное образовательное \\ учреждение «Сахалинский политехнический центр № 5»
}

Аннотация: в данной статье раскрывается вопрос о необходимости использования дистанционных образовательных технологий в обучении лиц с ограниченными возможностями здоровья (ОВ3). Предлагаемая статья имеет цель содействия повышению уровня профессиональной компетентности педагогов через освоение новых подходов к организации обучения; теоретически обосновать и практически разработать дистанционный курс обучения лиц с ограниченными возможностями здоровья. Для достижения цели поставлены следующие задачи:

- обоснование организации дистанционного обучения ребят с ограниченными возможностями здоровья;

- определение условий, особенностей работы преподавателя;

- разработка дистанционного курса: тематического материала (курса), контрольно-оценочных средств и фондов, адаптированных для лиц с ОВ3;

- реализация дистанционного курса. Категория обучающихся: профессиональная подготовка по профессиям рабочих, должностям служащих из числа выпускников специальной (коррекционной) образовательной школы VIII вида.

Ключевые слова: ОВ3 - лица с ограниченными возможностями здоровья, индивидуальный подход, интерактивные средства обучения, адаптированная образовательная программа, информационно-образовательная реабилитационная среда, дистанционное обучение, дистанционное образование, дистанционные образовательные технологии.

\section{THE USE OF DISTANCE LEARNING TECHNOLOGIES IN TEACHING PERSONS WITH DISABILITIES}


Abstract: this article reveals the question of the need to use distance learning technologies in teaching people with disabilities (HIA). The proposed article aims to promote the level of professional competence of teachers through the development of new approaches to the organization of training; theoretically substantiate and practically develop a distance learning course for people with disabilities. To achieve the goal, the following tasks are set:

- обоснование justification of the organization of distance learning for children with disabilities;

- определение determination of the conditions and features of the teacher's work;

- дистанционного development of a distance learning course: thematic material (course), control and evaluation tools and funds adapted for persons with disabilities;

- implementation of a distance learning course. Category of students: professional training in the professions of workers, positions of employees from among graduates of a special (correctional) educational school of the VIII type.

Key words: HIA - persons with disabilities, individual approach, interactive learning tools, adapted educational program, information and educational rehabilitation environment, distance learning, distance education, distance learning technologies.

Актуальность темы. В соответствии с Федеральным законом РФ от 29 декабря 2012 г. N 273-Ф31 [1, ст.79] «Об образовании в РФ» в статье 79 отражены вопросы организации получения образования детьми с ограниченными возможностями здоровья. В статье ратифицируется право получения образования, его доступность, особенности организации образовательного процесса для детей - инвалидов и детей с ограниченными возможностями здоровья.

Особую актуальность реализация права на получение образование ребят с ограниченными возможностями здоровья приобретает в связи с Федеральным законом «О ратификации конвенции о правах инвалидов» от 3 мая 2012 года. Государства, поддерживающие Конвенцию, обязуются развивать инклюзивное образование, то есть образование лиц с ограниченными возможностями здоровья наравне и вместе с обычными детьми. Обучающиеся с ограниченными возможностями здоровья могут реализовать свой потенциал лишь при условии вовремя начатого и адекватно 
организованного обучения и воспитания - удовлетворения как общих с нормально развивающимися обучающимися, так и их особых образовательных потребностей, заданных характером нарушения их развития.

Обучающийся с ограниченными возможностями здоровья (ОВ3) - это физическое лицо, имеющее недостатки в физическом и/или психологическом развитии, подтвержденные психолого-медико-педагогической комиссией и препятствующие получению образования без создания специальных условий [3].

Содержание образования и условия организации обучения и воспитания обучающихся с ограниченными возможностями здоровья определяются адаптированной образовательной программой. Адаптированная образовательная программа - это образовательная программа, адаптированная для обучения лиц с ограниченными возможностями здоровья с учетом особенностей их психофизического развития, индивидуальных возможностей и при необходимости обеспечивающая коррекцию нарушений развития и социальную адаптацию указанных лиц.

Под специальными условиями для получения образования обучающимися с ограниченными возможностями здоровья понимаются условия обучения, воспитания и развития, включающие в себя использование специальных образовательных программ и методов обучения и воспитания, учебников, учебных пособий и дидактических материалов, практико-ориентированных заданий, специальных технических средств обучения коллективного и индивидуального пользования, предоставление услуг помощника, оказывающего обучающимся необходимую техническую помощь, проведение групповых и индивидуальных коррекционных занятий. Для создания специальных условий необходимо создать в образовательной организации информационно-образовательную реабилитационную среду для лиц с ОВ3.

Информационно-образовательная реабилитационная среда - это совокупность общедидактических и специальных информационных технологий, дистанционных образовательных технологий, информационно-технических средств обучения, учебно-методического обеспечения, направленных на повышение эффективности и доступности образовательного процесса для лиц с ОВ3. Основные функции информационно-образовательной реабилитационной среды для лиц с ОВЗ: 
коммуникативная, образовательная, развивающая, компенсаторная, социализирующая.

Современные информационно-коммуникационные технологии для образования лиц с ОВЗ включают:

- традиционные виды технологий (компьютеры, веб-браузеры, текстовые процессоры, интерактивные панели с набором приложений, электронные доски и мобильные телефоны со встроенными функциями повышения доступности);

- ассистивные технологии (аудиофоны, программы для чтения с экрана, адаптивные клавиатуры, дополнительные коммуникационные устройства);

- доступные носители и форматы (видеоматериалы, система доступной цифровой информации).

Дистанционное обучение выступает в роли не только надежной альтернативы традиционному образованию, но и уникальной системы интеграции, где обучающиеся могут участвовать в учебном процессе, не присутствуя на занятиях в образовательном учреждении.

Термин «дистанционное обучение» часто используется как синоним «дистанционного образования», однако они не идентичны. Дистанционное образование представляет собой систему и процесс предоставления учебных материалов для обучающихся. В последнее время данный вид образования произвел революцию в связи с активным развитием в области информационных и коммуникационных технологий (ИКТ) и превратился в уникальный и комплексный феномен обучения и преподавания. Дистанционное обучение характеризуется как: разделение преподавателя, обучающегося и учебных материалов в пространстве и во времени; взаимодействие (педагог - обучаемый - материалы) с помощью одной или нескольких технологий (это не только электронные технологии).

Система дистанционного обучения может обеспечить:

- выбор удобного времени и места для обучения как для преподавателя, так и для обучающегося;

- прочное усвоение знаний;

- $\quad$ контакт преподавателя с обучаемым по мере необходимости, если он работает и контактирует с преподавателем;

- индивидуализацию обучения. 
Информационные ресурсы: базы данных и знаний, компьютерные, в том числе мультимедиа, обучающие и контролирующие системы, видео- и аудиозаписи, электронные библиотеки [2] - вместе с традиционными учебниками и методическими пособиями создают уникальную распределенную среду обучения, доступную широкой аудитории лиц с ОВ3.

\section{Этапы технологии дистанционного обучения лиц с ОВ3}

1. Подготовительный этап включает в себя сбор информации о ребятах, для которых педагог должен стать собеседником и другом. Знакомство с картой здоровья обучающегося [2]. Перед составлением расписания и календарно-тематического планирования (адаптированной рабочей программы) необходимо изучить особенности здоровья каждого обучающегося.

2. Составление календарно-тематического планирования (можно и на каждого обучающегося) с указанием нумерации уроков, тем разделов, тем уроков, предполагаемых дат уроков.

3. Составление расписания (согласуется с родителями (опекунами), а также необходимо учитывать все возможности обучающихся и нормативы СанПин.

4. Этап подбора тестовых и практико-ориентированных заданий, упражнений и вариантов производственных ситуаций по дисциплинам [2].

5. Дистанционные уроки. Каждый урок включает: лекционный материал; тренировочные задания (с образцами, выполненными в виде графических файлов, чтобы обучающийся мог самостоятельно проверить правильность их выполнения); формы оценки заданий.

6. Блок содержания курса (лекции, инструкции, источники, методические рекомендации, учебные пособия, рабочие тетради) (Приложение 1).

7. Блок контроля:

- текущий (контрольная работа, веб-квест, реферат, ситуационный анализ, тест, консультации on-line);

- итоговый (круглый стол, лабораторная, практическая работы, дистанционный урок).

8. Организационный блок (документация учебного процесса, текущие объявления).

Блоки $1-4,8$ представляют собою методическую работу до проведения курса (подготовку), блоки 5 и 6 - проведение курса, и блок 7 - фиксирование результатов. 
Для реализации дистанционного обучения преподаватель должен знать образовательный сегмент сети Интернет [4], ориентироваться в педагогических сетевых сообществах, иметь навыки проведения образовательного процесса с помощью информационно-коммуникационных технологий, знать и уметь применять педагогические технологии дистанционного обучения, уметь преподавать свой предмет в любой форме с помощью любых средств общения (Приложение 2).

Показателем результативности и эффективности дистанционного обучения считается повышение информационной компетенции обучающихся, формирования новых путей познания мира, расширение кругозора, отсутствие страха перед учебными дисциплинами или преподавателем, создание ситуации «успешного обучающегося», отсутствие неуспевающих. Обучающиеся, их родители (опекуны) с одобрением приняли данную форму обучения. Рекомендации по организации деятельности педагогов и специалистов служб сопровождения процесса профессионального обучения лиц с ОВ3 при переходе на электронное обучение с использованием дистанционных образовательных технологий и ресурсов были включены в рабочие программы учебных дисциплин и профессиональных модулей (Приложение 3).

\section{Проблемы}

- Компьютерная неграмотность (как обучающихся, так и их родителей (опекунов).

- На начальном этапе тратилось много времени на объяснение, что такое скайп, как там зарегистрироваться, как в поисковике найти нужную образовательную среду и электронную почту.

- Качество Интернет - соединения (сбои).

- Поломка и замена дорогостоящего оборудования.

В заключение следует отметить, что, несмотря на ряд трудностей, и проблем, с которыми мы столкнулись при организации и проведении дистанционных уроков, такая форма обучения востребована в социуме и дистанционное обучение успешно обеспечивает социализацию лиц с ОВ3, дает возможность получить полноценное образование и выбрать дальнейший путь. 


\section{Список литературы}

1. Федеральный закон Российской Федерации от 29 декабря 2012 года № 273 - ФЗ (ред. от 29.12.2017) «Об образовании в Российской Федерации», Федеральный закон от 31.07.2020 № 304-Ф3 «О внесении изменений в Федеральный закон «Об образовании в Российской Федерации» по вопросам воспитания обучающихся».

2. Агаев В.Т. Методические рекомендации по подготовке материалов для учебных аудио-видеосредств. - М.: МИЭП, 2008.

3. Быков Д.А. Дети с ограниченными возможностями и общество // Дополнительное образование. - 2006. - № 1. (http://www.e-joe.ru/sod/97/4_97/ st096.html), дата обр. к д-ту 13.03.2012г.

4. Полат Е.С. «Дистанционное обучение: организационные и педагогические аспекты». - М.:ИНФО, 2006. 